\title{
Does Recognition Memory Improve with Age?
}

\author{
Catherine Sophian \\ Carnegie-Mellon University \\ AND \\ JAMES W. Stigler \\ University of Michigan
}

\begin{abstract}
In order to test the hypothesis that recognition is a developmentally stable component of the memory system, age differences in recognition of faces were examined while controlling for nonmemory factors that might contribute to differences between the groups. Three groups of children (mean ages: 3 years, 4 months; 4 years, 9 months; and 6 years, 11 months) and a group of college students were tested on a recognition task and a similar matching task. The results indicated no change in recognition across the preschool years but an improvement from the later preschool period to the first grade. Further analyses indicated that this improvement was not due to changes in decision criteria or perceptual skills. These findings call into question the view that recognition is a developmentally invariant component of the memory system.
\end{abstract}

Recognition has often been described as a primitive, developmentally stable component of memory (Brown, 1975; Olson, 1976; Perlmutter \& Lange, 1978; Piaget \& Inhelder, 1973). This account has been based in part on reports of high levels of recognition performance in young children, approximating those of adults (Brown \& Campione, 1972; Brown \& Scott, 1971), and in part on analyses of recognition which have led some to conclude that it should be relatively insensitive to developmental change (Brown, 1975; Piaget \& Inhelder, 1973). The latter line of reasoning generally hinges on the notion that recognition does not require sophisticated retrieval processes and hence is less dependent on developmentally advanced evocative processes (Piaget \& Inhelder, 1973) or mnemonic strategies (Brown, 1975) than other forms of memory.

This view of recognition has recently been called into question, how-

The authors would like to thank Henry Wellman for many helpful suggestions. Reprint requests should be sent to: C. Sophian, Department of Psychology, Carnegie-Mellon University, Pittsburgh, PA 15213. 
ever (Mandler \& Robinson, 1978). It has been noted that ceiling effects are often present on recognition tasks and could mask age differences (Brown, 1975; Mandler \& Robinson, 1978). Moreover, several investigators have in fact observed age-related improvements in recognition performance (Dirks \& Neisser, 1976; Mandler \& Robinson, 1978; Perlmutter \& Myers, 1974, 1976; Tversky \& Teiffer, 1976).

The hypothesis of a basic, developmentally stable, recognition process, however, need not predict that age differences will never emerge on recognition tasks. Clearly, age differences might result from other components of task performance even if recognition itself were invariant. Three major factors which might contribute to such extraneous age differences are differences in the use of verbal labels, in decision criteria, and in perceptual skills.

Perlmutter and Myers (1976) have presented evidence that differential verbal labeling is not responsible for age differences in recognition, at least across the preschool years. They observed comparable spontaneous labeling by younger and older preschoolers and no facilitation from experimenter-provided labels at either age.

The role of decision criteria in recognition differences is more problematic, however. Signal detection analyses have revealed some differences in decision criteria among elementary school children but also independent differences in a measure of the discriminability of old vs new items (Berch \& Evans, 1973). With very young children, signal detection analyses have not indicated age-related differences in response bias, but they have not always confirmed differences in recognition accuracy either (Perlmutter \& Myers, 1976). Moreover, differences in response bias were obtained when a more direct measure, based on the overall proportion of acceptances vs rejections, was used (Perlmutter \& Myers. 1974, 1976). The latter measure may be more trustworthy than the signal detection analysis, since the measures derived from that analysis depend critically upon assumptions of normality that may not have been adequately met. More generally, signal detection analyses may be difficult to apply properly to developmental work because they typically require large numbers of observations and well-practiced observers (Green \& Swets, 1974). Unfortunately, without signal detection analyses there is no direct way to separate the contributions of differences in decision criteria and of discriminability differences to age differences in performance.

The possibility that age differences in recognition performance may derive from improvements in perceptual skills rather than in memory has not been studied directly. The hypothesis is consistent, however, with observations of developmental improvements in the exhaustiveness with which children scan displays in a matching task (Vurpillot, 1976). Differences in visual scanning seem especially likely to contribute to age 
differences on recognition tasks involving complex pictorial stimuli, such as those used by Dirks and Neisser (1976) and Mandler and Robinson (1978).

The purpose of the present research was to reexamine the hypothesis that recognition is a developmentally stable component of the memory system. To this end, recognition performance was compared across age groups while taking account of possible extraneous sources of age differences. Particular attention was given to the role of response biases and perceptual skills in developmental increases in recognition performance. Verbal skills were not examined directly, but we attempted to minimize their influence by using stimuli that could not be easily differentiated by verbal labels (faces).

A forced-choice rather than a yes-no test format was adopted in order to prevent shifts in decision factors (such as conservatism or confidence) from affecting the pattern of performance across age (Perlmutter \& Myers, 1976). Of course, response biases may still affect performance in the form of position preferences, but we hoped that this type of response bias would be smaller and less subject to developmental change. The extent to which it did contribute to age differences in recognition performance was assessed through an analysis of covariance.

To control for age differences in perceptual skills, subjects were tested on a matching task as well as the recognition task. The two tasks were as comparable as possible. The main difference was that on the matching task the target stimulus remained visible as the test pair was presented, while on the recognition task the target stimulus was removed before presenting the test pair. We assumed that the matching task should have involved essentially the same perceptual processes as the recognition task, but without the memory processes. Accordingly, any age differences in recognition that result from perceptual differences were expected to show up also on the matching task, while those that result from memory differences were expected to appear only in recognition.

\section{METHOD}

\section{Subjects}

Twenty children in each of three age groups were tested: younger preschoolers, who were between 2 years, 11 months and 3 years, 9 months (mean: $3 ; 4$ ); older preschoolers, 4 years, 6 months to 5 years, 1 month of age (mean: 4;9); and first graders, 6 years, 3 months to 8 years, 1 month of age (mean: 6:11). A group of 20 college students from an Introductory Psychology course was also tested.

\section{Materials}

The same stimuli were used for the matching and the recognition task. These stimuli were faces constructed from an Identikit. Two blocks of 
stimuli were constructed, each consisting of 12 targets plus corresponding target-distractor choice pairs. Half the distractors within each block differed from the corresponding target stimulus in one feature (eyes, nose, or mouth), while the others differed in all three features. These kinds of target-distractor pairs were selected on the basis of pilot testing in order to minimize floor effects on the recognition task and ceiling effects on the matching task. An example of each type of target-distractor pair is presented in Fig. 1.
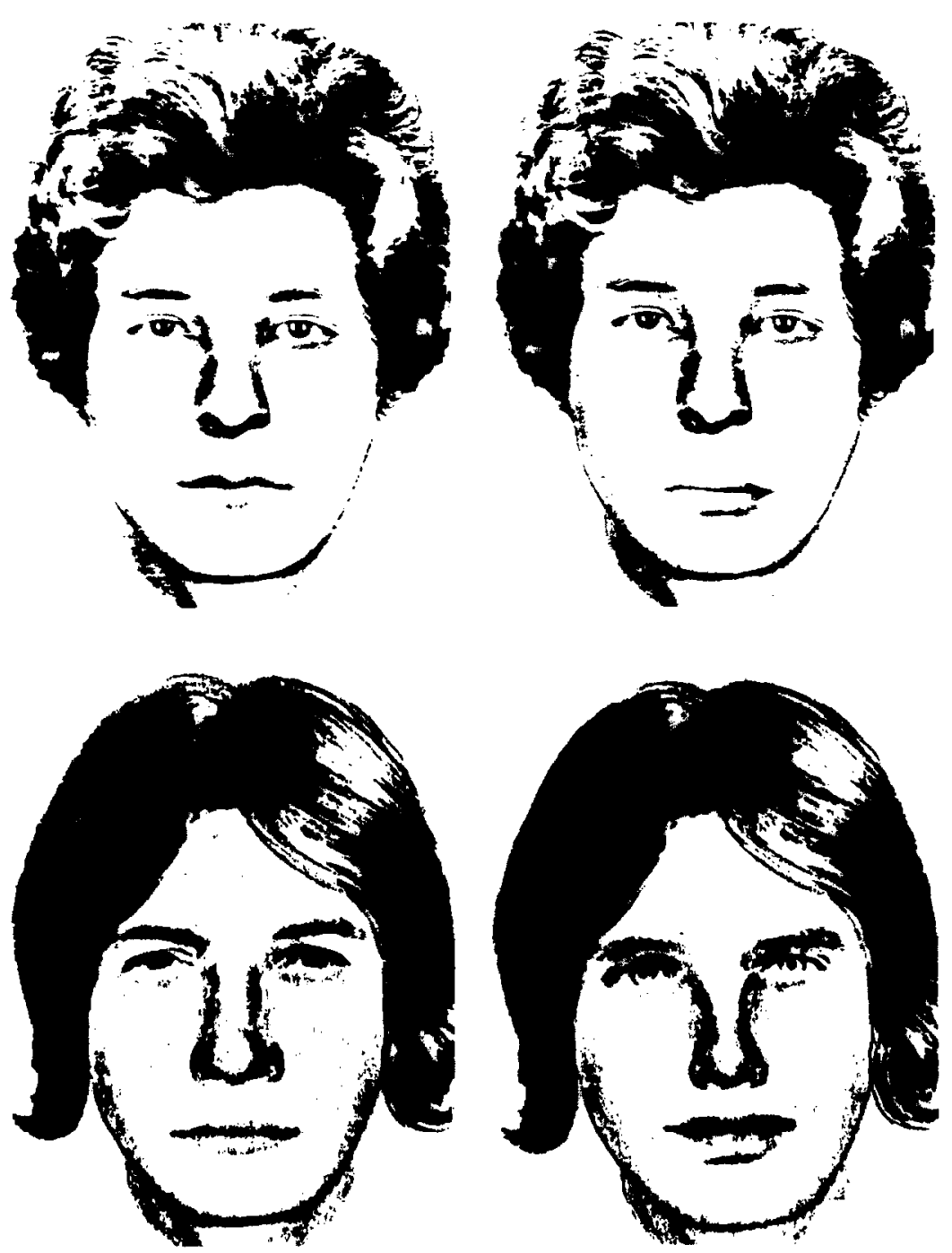

Fig. 1. Examples of target-distractor pairs differing in one (top) or three (bottom) features. 


\section{Procedure}

Subjects were tested by a male experimenter. Children were tested individually, college students in two large groups. All subjects received a block of 12 matching trials and a block of 12 recognition trials, with the order counterbalanced across subjects. Block 1 stimuli were always used for the first task administered (matching or recognition) and Block 2 stimuli for the second task. The order of items within each block was randomly determined. Target positions within test pairs was counterbalanced over trials.

On matching trials, a target stimulus and its corresponding choice pair were presented simultaneously. The subject was asked to indicate which of the choice stimuli was "just like" the target. Subjects were allowed as much time as they needed to make a response. On recognition trials, the target stimulus was presented alone for about $3 \mathrm{sec}$ and then turned face down. After a 3-sec delay, subjects were shown the test pair and asked to indicate which one was "just like" the target they had just seen. Again, there was no time limit on responses. Each block of trials was preceded by two practice trials with schematic faces that were easily discriminated. All subjects performed perfectly on practice trials.

\section{RESULTS}

The principal results are summarized in Table 1, which indicates the mean number of correct responses on each task at each age level. Although there were some floor effects in children's recognition performance on the high-similarity items, performance on the lower-similarity items was well above chance. The possibility of ceiling effects is more difficult to evaluate. Inspection of the means suggests that performance in five cells is at ceiling: the performance of first graders on matching of the lower-similarity items, and the performance of college students on both tasks and both item types. These cells had the lowest standard deviations, averaging .5358 as opposed to an average standard deviation of 1.1425 for the remaining cells. Yet, these were the only cells in which the cell mean was within one standard deviation of perfect performance.

Because the college students were performing at ceiling on all measures, their data were considered uninterpretable and were not analyzed further. It was considered feasible to interpret the data of the remaining groups, however, since there were only occasional ceiling or floor effects in their data and all of these groups performed above chance but below ceiling on at least one set of matching items and one set of recognition items. Preliminary analyses included all of the data from the child groups, but care was taken to confirm the results with more specialized analyses based on only those parts of the data which were not contaminated by either floor or ceiling effects. 
TABLE 1

Mean Number of Correct Responses on Matching and Recognition Tasks at Each Age Level

\begin{tabular}{|c|c|c|c|}
\hline \multirow[b]{2}{*}{ Age group } & \multirow[b]{2}{*}{ Distractor type } & \multicolumn{2}{|c|}{ Task } \\
\hline & & Matching & Recognition \\
\hline \multirow[t]{3}{*}{$\begin{array}{l}\text { Younger } \\
\text { preschoolers }\end{array}$} & $\begin{array}{l}\text { One feature changed } \\
(\text { maximum }=6)\end{array}$ & 3.20 & 3.15 \\
\hline & $\begin{array}{l}\text { Three features changed } \\
(\text { maximum }=6)\end{array}$ & $4.05^{*}$ & $4.15^{*}$ \\
\hline & $\begin{array}{l}\text { All items combined } \\
\quad(\text { maximum }=12)\end{array}$ & $7.25^{*}$ & $7.30^{* *}$ \\
\hline \multirow[t]{3}{*}{$\begin{array}{l}\text { Older } \\
\text { preschoolers }\end{array}$} & $\begin{array}{l}\text { One feature changed } \\
(\text { maximum }=6)\end{array}$ & $4.25^{*}$ & 2.75 \\
\hline & $\begin{array}{l}\text { Three features changed } \\
(\text { maximum }=6)\end{array}$ & $5.00^{*}$ & $4.00^{*}$ \\
\hline & $\begin{array}{l}\text { All items combined } \\
\quad(\text { maximum }=12)\end{array}$ & $9.25^{*}$ & 6.75 \\
\hline \multirow[t]{3}{*}{ First graders } & $\begin{array}{l}\text { One feature changed } \\
(\text { maximum }=6)\end{array}$ & $5.05^{*}$ & 3.40 \\
\hline & $\begin{array}{l}\text { Three features changed } \\
\quad(\text { maximum }=6)\end{array}$ & $5.70^{*}$ & $4.95^{*}$ \\
\hline & $\begin{array}{l}\text { All items combined } \\
\quad(\text { maximum }=12)\end{array}$ & $10.75^{*}$ & $8.35^{*}$ \\
\hline \multirow[t]{3}{*}{ College students } & $\begin{array}{l}\text { One feature changed } \\
(\text { maximum }=6)\end{array}$ & $5.90^{*}$ & $5.50^{*}$ \\
\hline & $\begin{array}{l}\text { Three features changed } \\
(\text { maximum }=6)\end{array}$ & $5.85^{*}$ & $5.65^{*}$ \\
\hline & $\begin{array}{l}\text { All items combined } \\
\text { (maximum }=12)\end{array}$ & $11.75^{*}$ & $11.15^{*}$ \\
\hline
\end{tabular}

* Significantly above chance, $p<.001$.

** Significantly above chance, $p<.01$.

The data from the three groups of children were analyzed in a 3 (age) $\times 2$ (task-order) $\times 2$ (task) $\times 2$ (distractor-type) analysis of variance, with task and distractor type as repeated measures. There were significant main effects of age, $F(2,54)=20.32, p<.001$, task, $F(1,54)$ $=35.0, p<.001$, and distractor type, $F(1,54)=40.99, p<.001$, and a significant age $\times$ task interaction, $F(2,54)=9.31, p<.001$. Matching increased significantly from the early to the later preschool period and from the later preschool period to the first grade. In contrast, recognition showed a nonsignificant decline over the preschool years but a significant improvement between the later preschool period and the first grade (Scheffé tests, $p=.05$ ). Matching was significantly better than recognition at the two older ages but not for the younger preschool group 
(Scheffé tests, $p=.05$ ). Performance was better when distractors differed from targets in three features rather than in only one.

As might be expected from the absence of interactions with distractor type in the overall analysis, the same pattern of results emerged in more specialized analyses designed to control for floor and ceiling effects. In particular, a 2 (age) $\times 2$ (task-order) $\times 2$ (task) analysis of variance on just the data from the two groups of preschoolers and the less similar sets of items again indicated an improvement in matching but not in recognition and an advantage for matching over recognition only at the older age level (age $\times$ task: $F(1,36)=4.41, p<.05 ;$ Scheffé tests, $p$ $=.05$ ). Likewise, a comparison of older preschoolers and first graders based on their matching performance on the higher-similarity items but their recognition performance on the lower-similarity items again indicated parallel improvements in both tasks (age: $F(1,36)=12.29, p<$ .001 , age $\times$ task: $F(1,36)=.09, p>.10)$.

There was a significant tendency for children to choose the stimulus on the right more often than would be expected by chance (or by correct responding) on matching, $t=2.14, p<.05$, and recognition, $t=4.15$, $p<.001$. This response bias did not differ across ages, $F<1$. Moreover, an analysis of covariance indicated that it did not account for the age differences in recognition. Response bias was not a significant covariate, $F(1,37)=.22, p>.10$, and age differences in recognition between older preschoolers and first graders remained significant even when it was statistically controlled, $F(1,37)=6.74, p<.01$.

Another analysis of covariance was carried out to determine whether age differences in children's recognition could be accounted for by differences in perceptual skills, as indicated by matching performance. This analysis again indicated significant effects of age, $F(2,56)=3.27, p$ $<.05$, and distractor type, $F(1,56)=19.71, p<.001$, on recognition performance. As before, recognition performance improved from the later preschool period to the first grade (Scheffé tests, $p=.05$ ), and it was better when distractors differed from targets in three features rather than in only one. The effect of the covariate was not significant, $F(1$, $56)=.37, p>.10$. The same results were obtained in another analysis of covariance including only the older preschoolers and the first graders, in which matching performance on just the lower-similarity items was the covariate and recognition performance on just the higher-similarity items was the dependent variable. Age differences in recognition were still significant, $F(1,37)=5.88, p<.05$, and the cffect of the covariate was not, $F(1,37)=.00, p>.10$.

Further evidence that differences in recognition could not be attributed to differences in matching skills was obtained by comparing the recognition performance of subgroups of the older preschoolers and the first 
graders who performed equally well on the matching task. It was possible to match 11 of the older preschoolers with first graders who produced the same number of correct responses to both the high-similarity and the lower-similarity matching problems. The mean matching scores for these subjects were 4.73 and 5.55 for lower- and higher-similarity items, respectively. The corresponding recognition scores were 2.64 and 3.91 for the preschoolers, and 3.36 and 4.82 for the first graders. A 2 (age) $\times 2$ (distractor type) analysis of variance on the recognition performance of these 22 subjects confirmed the earlier analysis. The first graders performed significantly better than the older preschoolers, $F(1,20)=$ $5.05, p<.05$, and performance was significantly poorer on the highsimilarity than the lower-similarity items, $F(1,20)=8.81, p<.01$. The same pattern of results was obtained when the groups were compared on their performance on just the lower-similarity items; however, the age difference was not quite significant, $F(1,21)=2.79, p=.11$.

\section{DISCUSSION}

Although the present results provide no evidence of developmental improvements in recognition over the preschool years, they do indicate improvements between the later preschool period and older ages. Moreover, while ceiling effects make it impossible to draw inferences about the basis for the superior performance of the college students, it is possible to evaluate a number of possible explanations for the improvement in recognition from the older preschool group to the first graders. As alternative accounts for this improvement are dismissed, the view that recognition is an invariant component of the memory system becomes increasingly difficult to maintain.

The improvement in recognition performance cannot be attributed to age differences in perceptual skills. Although perceptual skills did improve with age, as indicated by performance on the matching task, this improvement was independent of the increase in recognition performance. Age differences in recognition were obtained even when differences in matching performance were statistically controlled, and they were present even within a subset of subjects who performed identically on the matching task.

The improvement in recognition also cannot be attributed to response biases. Differences in decision factors such as conservatism which were observed in previous studies were controlled in this study by using a forced-choice rather than a yes-no testing procedure. Even so, response biases could still occur and indeed significant response biases were found. They did not differ across the three groups of children, however, and did not account for differences in recognition performance.

Although effects of verbal labeling were not examined directly in this study, they also appear unlikely to account for the observed difference 
in recognition. The faces used as stimuli could not be readily differentiated by verbal labels, and indeed there was no indication that any subject attempted to label them.

It is also unlikely that differences in knowledge were responsible for the recognition differences between the preschoolers and the first graders. Faces are highly familiar stimuli for which even infants appear to have schemas (Fagan, 1972); hence, important differences in knowledge are not likely to exist among the groups of children studied here. In addition, there is evidence that knowledge is not an important factor in children's recognition of faces. Chi (1977) studied memory for familiar and unfamiliar faces using a memory span task in which subjects had to select and correctly order a set of faces from a larger set of alternatives. Although familiarity had some effect on adults' ability to order the faces, it did not affect the ability of cither 5-year-olds or adults to select (i.e., recognize) the correct faces (irrespective of order) from the larger set. Chi's results thus suggest that knowledge does not have much effect on face recognition. Since her familiar and unfamiliar faces also differed in that the subjects knew names for the familiar faces but not the unfamiliar ones, the results also suggest that labeling may not be a very potent variable in face recognition.

A final possibility is that age differences in recognition result from differences in visual processing speed. This factor would affect recognition but not matching because of the limited presentation time in the former task. We have three reasons for rejecting this explanation. First, the presentation interval was not designed to limit children's perceptual processing of the target but was chosen on the basis of pilot work because it represented about the longest time that children would continue to look at the faces. Indeed, several of the preschoolers had to be encouraged to continue looking at the stimulus throughout the presentation interval. None of the children gave any indication that they felt they were being interrupted when the target was turned over. Second, if encoding speed were the critical factor, we might expect to find smaller age differences on the lower-similarity items, where less information was needed to discriminate the targets from the distractors. Yet, even with ceiling effects limiting the size of the age differences on these items, the observed differences was actually larger than on the higher-similarity items (though not significantly so). Finally, there is independent evidence from other work which suggests that perceptual processing speed is fairly constant across age (Haith, 1971).

With the rejection of alternative explanations for the differences in recognition performance observed in this study, the hypothesis that recognition itself changes with age becomes increasingly plausible. While it is impossible to dismiss all alternative accounts, the present study does rule out several important factors that have not been adequately taken 
into account in previous work. As a result, this study provides a stronger basis for calling into question, if not definitively ruling out, the hypothesis that recognition is a developmentally invariant component of the memory system.

This study did not reveal age differences in recognition between the two preschool groups, although such differences have been obtained in previous research (Perlmutter \& Myers, 1974, 1976). This discrepancy might be due to our use of a forced-choice rather than a yes-no testing procedure, implying that the previous findings reflected differences in decision criteria rather than in memory processes. However, it is also possible that the previous findings did derive from memory differences that were simply not manifested on our task. An important difference between the present study and earlier work is that here the items were presented and tested one by one, whereas in previous studies a whole list of items has been presented before testing any. The item-wise testing procedure was used to maintain maximum comparability to the matching task. It may have militated against the emergence of age differences, however, by minimizing the retention interval and the number of items that had to be held in memory. It should be noted, though, that in spite of this characteristic of the present task, our procedures were sensitive enough to reveal differences between the older preschoolers and the first graders.

In summary, the present research revealed age differences in recognition between the later preschool period and the first grade but not between younger and older preschoolers. While the latter finding cannot be taken to disconfirm previous findings of age differences in preschoolers' recognition, the former result does call into question characterizations of recognition as an invariant component of the memory system. Age differences were obtained despite the inclusion of controls for nonmemory factors that might contribute to age differences in performance. Although the invariance-of-recognition hypothesis cannot be definitively rejected on the basis of these data, it is certainly rendered less plausible. The challenge for those who wish to retain the invariance hypothesis is to show how nonmemory factors can account for the age differences that have been repeatedly observed.

\section{REFERENCES}

Berch, D. B., \& Evans, R. C. Decision processes in children's recognition memory. Journal of Experimental Child Psychology, 1973, 16, 148-164.

Brown, A. L. The development of memory: Knowing, knowing about knowing, and knowing how to know. In H. W. Reese (Ed.), Advances in child development and behavior (Vol. 10). New York: Academic Press. 1975.

Brown, A. L., \& Campione. J. C. Recognition memory for perceptually similar pictures in preschool children. Journal of Experimental Psychology, 1972, 95, 55-62. 
Brown, A. L., \& Scott, M. S. Recognition memory for pictures in preschool children. Journal of Experimental Child Psychology, 1971, 11, 401-412.

Chi, M. T. H. Age differences in memory span. Journal of Experimental Child Psychology, $1977,23,266-281$.

Dirks, J., \& Neisser, U. Memory for objects in real scenes: The development of recognition and recall. Journal of Experimental Child Psychology, 1977. 23, 315-328.

Fagan, J. F. Infants' recognition memory for faces. Journal of Experimental Child Psychology, 1972, 14, 453-476.

Green, D. M., \& Swets, J. A. Signal detection theory and psychophysics. Huntington, N.Y.: Krieger, 1974.

Haith, M. M. Developmental changes in visual information processing and short-term visual memory. Human Development, 1971, 14, 249-261.

Mandler, I. A., \& Robinson, C. A. Developmental changes in picture recognition. Journal of Experimental Child Psychology, 1978, 26, 122-136.

Olson, G. M. An information processing analysis of visual memory and habituation in infants. In T. J. Tighe \& N. Leaton (Eds.), Habituation: Perspectives from child development, animal behavior, and neurophysiology. Hillsdale, N.J.: Erlbaum, 1976.

Perlmutter, M., \& Lange, G. A developmental analysis of recall-recognition distinctions. In P. A. Ornstein (Ed,), Memory development in children. Hillsdale, N.J.: Erlbaum, 1978.

Perlmutter, M., \& Myers, N. A. Recognition memory in two- to four-year-olds. Developmental Psychology, 1974, 3, 447-450.

Perlmutter, M., \& Myers, N. A. Recognition memory in preschool children. Developmental Psychology, 1976, 12, 271-272.

Piaget, J., \& Inhelder, B. Memory and intelligence. New York: Basic Books, 1973.

Tversky, B., \& Teiffer, E. Development of strategies for recall and recognition. Developmental Psychology, 1976, 12, 406-410.

Vurpillot, E. The visual world of the child. New York: International Universities Press, 1976.

ReCeived: May 23, 1980; Revised: October 14, 1980, December 16, 1980. 